\title{
Therapy talk and talk about therapy: Client-identified important events in psychotherapy
}

\author{
Erika Viklund
}

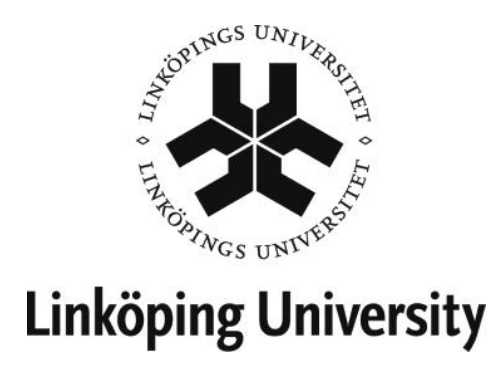

Linköping University

Department of Behavioural Sciences and Learning

Linköping 2013 
Faculty of Arts and Sciences, FiF-avhandling No. 112

Licentiate Thesis

Distributed by:

Department of Behavioural Sciences and Learning

Linköping University

SE -581 83 Linköping

Erika Viklund

Therapy talk and talk about therapy: Client-identified important events in psychotherapy

Upplaga 1:1

ISBN 978-91-7519-452-3

ISSN 1401-4637

(C) Erika Viklund

Department of Behavioural Sciences and Learning, 2013

Printed by: LiU-Tryck, Linköping 2014 
We shall not cease from exploration And the end of all our exploring Will be to arrive where we started And know the place for the first time.

T. S. Eliott, Little Gidding 



\section{Abstract}

Capturing and studying the moments in psychotherapy that clients find most important can help us understand more about how psychotherapy works, what the curative ingredients are, and by what processes they are mediated. Qualitative research in this area has, so far, mainly focused on describing, and categorizing clients' experiences of important factors and events. The methods employed to analyse the data have been rather limited in variation and are usually based on a realist epistemology, according to which data are basically treated as reflections of the clients' actual experiences. This entails a risk of overlooking and obscuring other aspects of therapy and the therapy process that are equally important to explore, for example the microprocesses of interaction within important events, or how clients' accounts of their experiences are shaped and limited by the context in which they are produced. The overall aim of this licentiate thesis was to explore client-identified important events in psychotherapy with a focus on studying therapy talk and talk about therapy from a social constructionist point of view, which would allow a closer exploration of the understudied areas mentioned above.

In Study I, Conversation Analysis was used to explore the interaction taking place between seven client-therapist dyads in 16 client-identified important events collected from their third sessions. The analysis identified that 12 of the events contained clients' expressions of disagreement. Three different ways that the therapists handled the disagreement were discerned: The first, and most common, way was to orient to the client's cues of disagreement by inviting the client to elaborate on his or her point of view and to establish a shared understanding acceptable to both participants. The second way was to orient to the client's disagreement cues but define the therapist's own point view as more relevant than the client's, and the third way was a single case in which the therapist did not in any way orient to the client's disagreement cues.

In Study II, two qualitative methods based on different epistemologies were used to analyse the same set of eight clients' accounts of 18 important events. The aim was to first identify what types of events clients describe as important, and then explore how their accounts of these events were contextually shaped and organized, 
and the consequences of this. The first analysis, a content analysis, yielded descriptions of five different types of events, which were similar to the ones found in previous research on important events. The second analysis, a discourse analysis, demonstrated how clients' accounts were not only influenced by the participants' ability to accurately remember and report their experience, but also by what was sayable within the context of the research interview. In conclusion, the two studies demonstrate how qualitative methods based on a socialconstructive perspective can contribute to our understanding of clientidentified important events by highlighting and describing participants' use of language in interaction, and its forms and functions within therapy sessions and in research interviews. The findings point out the need to broaden the range of qualitative methods used in psychotherapy research in general and indicate the potential value of methods like CA and DA to psychotherapy process research and research on important events in particular.

Keywords: psychotherapy process, important events, clients' experiences, conversation analysis, discourse analysis, qualitative methods 


\section{Included papers}

\section{Paper I}

Viklund, E., Holmqvist, R., \& Zetterqvist-Nelson, K. (2010). Clientidentified important events in psychotherapy: Interactional structures and practices. Psychotherapy Research, 20(2), 151-164.

\section{Paper II}

Viklund, E., Holmqvist, R., \& Zetterqvist-Nelson, K. (Submitted). Two ways of analyzing clients' accounts of important events in psychotherapy. 



\section{Table of contents}

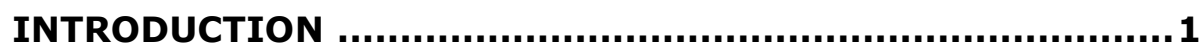

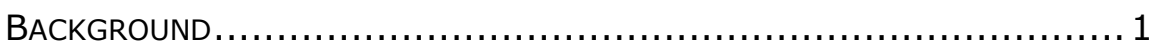

PREVIOUS RESEARCH ON CLIENTS' EXPERIENCES OF PSYCHOTHERAPY ........ 3

Quantitative process-outcome research .......................... 3

Helpful factors research...................................... 4

Helpful factors in different types of therapy ...................... 5

Hindering factors ................................................. 6

Helpful and hindering factors in different therapy modalities and in therapy with children and adolescents .................... 8

WHAT DO WE KNOW AND WHERE DO WE GO FROM HERE? .................. 10

SOCIAL CONSTRUCTIONIST PERSPECTIVES IN PSYCHOTHERAPY RESEARCH . 12

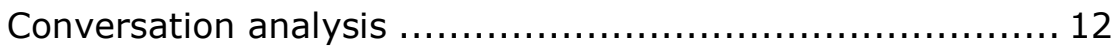

Discourse analysis ......................................... 14

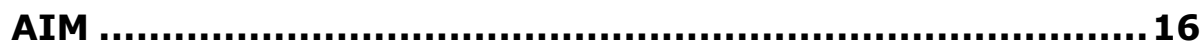

METHODOLOGICAL APPROACH...................................... 16

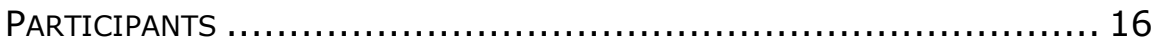

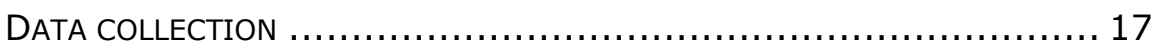

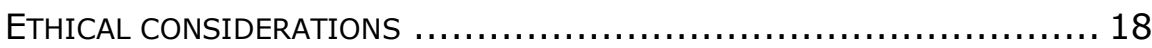

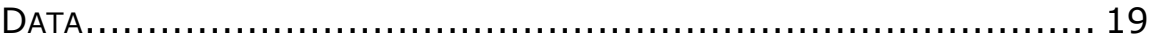

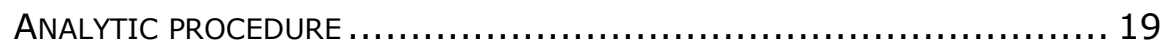

Analysis of the videotaped events ............................. 19

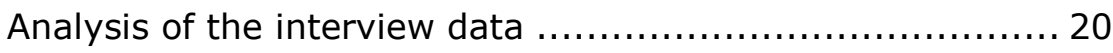

SUMMARY OF INCLUDED STUDIES ................................. 22

PAPER I: CLIENT-IDENTIFIED IMPORTANT EVENTS IN PSYCHOTHERAPY:

INTERACTIONAL STRUCTURES AND PRACTICES. ........................ 22

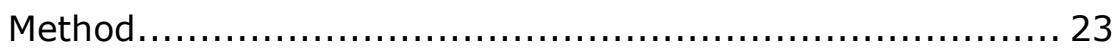

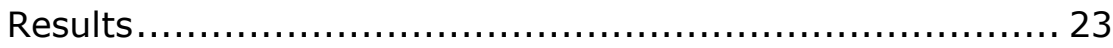

Discussion ...................................................... 23

PAPER II: TWO WAYS OF ANALYZING CLIENTS' ACCOUNTS OF IMPORTANT

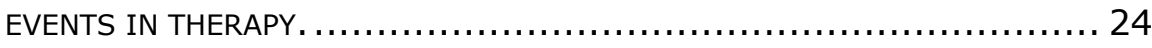

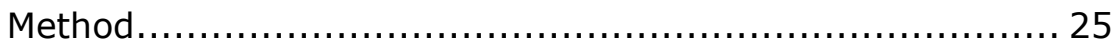

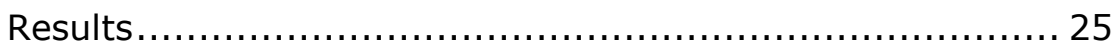


Discussion

CONCLUSIVE DISCUSSION AND IMPLICATIONS FOR

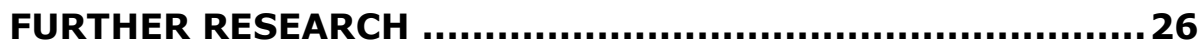

SHIFTING FOCUS - FROM CATEGORIZATION TO CONTEXTUALITY ............ 27

QUALITATIVE METHODS IN PSYCHOTHERAPY PROCESS RESEARCH.......... 28

LIMITATIONS, GENERALIZABILITY, AND THE CLAIMS AND AMBITIONS OF CA

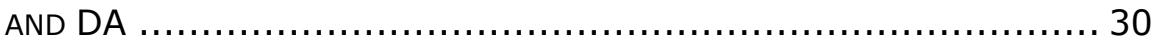

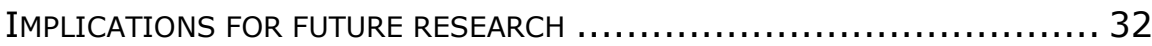

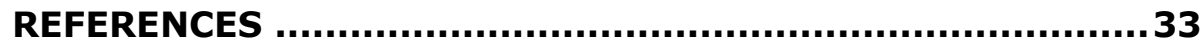

ACKNOWLEDGEMENTS IN SWEDISH..............................41 


\section{Introduction}

Understanding more about clients' experiences of therapy is an important focus for psychotherapy research. The ability to respond effectively and flexibly to the clients' needs is a central aspect of therapeutic skill that, among other things, requires a good understanding of the range and forms of potential client experience. Moreover, in most psychotherapies, regardless of theoretical orientation, clients' experiences are seen both as an important source of information guiding the therapist's interventions and general insession behavior, and as an area in which it is important to achieve change. In short, the rational underlying research on clients' experiences in therapy is that they can help us identify ingredients that are central to change and outcome and the moments in which those ingredients are most likely present. If they can be successfully captured and studied, we may learn more about how psychotherapy works, what the curative ingredients are, and how and by which processes they are mediated. This may in turn lead to clinically useful guidelines on how to practice psychotherapy in more effective ways.

As a clinical psychologist and psychotherapist with several years' experience of therapeutic work with patients and clients from various age groups and in various setting, I have learned the importance of being perceptive of and attuned to the client's experiences but I have also come to appreciate how difficult that can sometimes be. This knowledge has led to an interest in the therapy process in general, and in clients' experiences of psychotherapy in particular. The overall aim of the present licentiate thesis is to explore client-identified important events in psychotherapy. Its starting point was an interest in clients' subjective experiences of therapy, particularly moments within sessions that the clients themselves find important. Along the way, that interest has widened to also include a methodological focus on how this can be qualitatively studied.

\section{Background}

The interest in clients' experiences of psychotherapy as a valuable focus for research dates back to the early days of Rogerian psychotherapy and, more specifically, to Lipkin's (1948) study of 37 male clients in person-centered therapy who were asked to describe their experiences of what had brought them to therapy, the therapy itself, and the changes following it. Before that, research focusing on the qualitative aspects of the actual processes of change 
or the clients' subjective ways of understanding and relating to therapy was rare. When the first modern psychotherapeutic techniques were born at the turn of the twentieth century, descriptions of psychotherapy and the psychotherapy process were mainly presented and discussed in case reports. In these, all accounts of interactions, experiences, important events, and understanding were typically based solely on the therapist's expert perspective. The development of learning-based and client-centered therapy approaches in the 1920s, 1930s and 1940s brought a greater emphasis than before on evaluating the effects of therapy. Cognitive and behavioral approaches developed rating scales and questionnaires that allowed a close monitoring of therapists' interventions and clients' response to treatment, and the research groups around Carl Rogers started to make audio-recordings of therapy sessions, which made the actual in-session interactions available for examination. However, most research on psychotherapy processes was still based on researchers' or non-participant experts' analyses of data from psychotherapies, which were seen as more objective and reliable than the participating clients' (or therapists') own reports and, thus, more suitable and trustworthy as empirical evidence.

In the 1950s and 1960s a research field focusing on clients' experiences started to evolve as part of the ongoing reaction against the dominating quantitative and experimental orientation in psychological research, which had focused mainly on measuring change. At about this time, the clients' perspective and an experiential perspective on the events of psychotherapy started to gain ground as important sources of information. Client and therapist versions of rating scales and questionnaires were developed, which allowed both the objective study of clients' and therapists' subjective experiences and comparisons of participants' and researchers'/observers' perspectives (see e.g. Orlinsky \& Howard, 1967; Snyder, 1961; Strupp, Fox, $\&$ Lessler, 1969). There were also a number of pioneering studies in group therapy in which clients' and therapists' written reports on their perceptions of important events were collected and classified into categories of therapeutic factors (see e.g. Berzon, Pious, \& Farson, 1963; Bloch \& Reibstein, 1980; Bloch, Reibstein, Crouch, Holroyd, \& Themen, 1979). Today, this area of research has grown substantially and encompasses a wide range of approaches to define, capture and analyze clients' experiences of important factors and processes in different types of therapy. 


\section{Previous research on clients' experiences of psychotherapy}

\section{Quantitative process-outcome research}

Several research paradigms aim to capture clients' and/or therapists' experiences of important aspects of the therapy or the therapy process. In fact, one of the most common types of psychotherapy research in general is quantitative process-outcome studies in which participants' experiences of important aspects of the therapy process are collected and used to predict post-therapy outcome. Most of these studies use theory or therapist/researcher perspectives rather than client perspectives to identify which processes, events or tasks are important, and use structured rating scales, checklists or inventories to obtain the clients' experiences. One of the variables most frequently studied in this way is probably the therapeutic alliance (see e.g. Horvath, Del Re, Flückiger, \& Symonds, 2011; Martin, Garske, \& Davis, 2000). Other examples are critical incidents or "key change events" that are identified and studied with the method task analysis (Greenberg, 2007), for instance problematic reactions (Rice \& Greenberg, 1984), and alliance ruptures (Safran \& Muran, 2003). In short, there are numerous studies of clients' experiences of therapy in which someone other than the client has defined which aspect of therapy or the therapy process is important, and in which the client's answers are restricted to the range of answers provided in the questionnaires or inventories constructed or selected by the researcher. There are literally thousands of findings from this type of process-outcome studies available in the literature, with different ways of identifying important aspects of the therapy process and with the experience measured from client, therapist and observer perspectives. Some of these results highlight the importance of the clients' experience for successful treatment. For example, it has been repeatedly demonstrated that in individual therapy, regardless of theoretical orientation, clients' ratings of the alliance (i.e. the collaboratively reached agreement between client and therapist regarding the tasks and goals of therapy, and the positive emotional bond between them) are better predictors of outcome than therapists' ratings (see e.g. Horvath et al., 2011). Research has also shown that clients' perceptions of therapist empathy and their experience of feeling understood by their therapists are related to positive outcome across theoretical orientations, treatment formats, and clients' level of severity (Elliott, Bohart, Watson, \& Greenberg, 2011). 


\section{Helpful factors research}

A different approach to capturing and studying clients' experiences of important aspects of therapy is to ask the clients what they found most important, helpful, or hindering in their therapy. This so called helpful factors research consists of two main approaches: First, clients can be asked posttherapy or after part of the therapy to describe what they found helpful, useful, important or hindering, or they can be asked to describe to what they attribute perceived changes over the course of therapy. This is done without necessarily specifying the distinct events within which the helpful factors occurred. Second, an event-based approach can be used in which clients are asked post-session to specify and describe the most helpful or important events that happened in the session and what made them helpful. This so called significant events research is, in turn, part of a broader research paradigm that focus on detailed analysis of specific episodes of therapy process and where the episodes selected for study can either be identified by clients or chosen on the basis of theoretical relevance. In both approaches to helpful factors research described above, the clients' answers are usually qualitatively analyzed and categorized into overviews of types of helpful factors, or into more detailed descriptions of specific types (or aspects) of factors or events, either by using more or less predetermined taxonomies or by defining, describing, labeling and categorizing the data in accordance with established qualitative research methods, mostly based on a realist epistemology.

There are several reviews on clients' experiences of helpful factors in therapy (See e.g. Elliott \& James, 1989; Greenberg, Elliott, \& Lietaer, 1994; Howe, 1993; McLeod, 1990; Rennie, 2002; Timulak, 2007, 2010). Elliott and James (1989) found that the factors most frequently perceived as helpful by the clients could be divided into two broad categories: relationship/affective factors and task/problem solving factors. In the first category, the factors most often mentioned by the clients were facilitative therapist characteristics, the opportunity to self-express freely, and experiencing a supportive relationship with the therapist. In the second category, the helping factors most frequently mentioned by the clients were gaining insight/selfunderstanding and being encouraged by the therapist to practice skills and insights from therapy in everyday life. Similar factors have been described in other reviews: Howe (1993) mentions for example experiencing the therapist as warm, friendly, genuine, interested and accepting, and getting the opportunity to express experiences and to explore thoughts and feelings and make sense of them as benefits of therapy and counseling frequently reported by clients. Greenberg et al. (1994) organized the five most frequently 
described or strongly rated helpful aspects from 14 studies of helpful factors in person-centered experiential therapies and found 14 types of helpful aspects that could be organized into four groups: positive relational environment (e.g. empathy), client's therapeutic work (e.g. exploration), therapist facilitation of client's work (e.g. giving feedback, fostering exploration), and client changes or impacts (e.g. experiencing positive feelings, gaining insight/awareness). Rennie (2002), who reviewed grounded theory studies on clients' experiences in humanistic therapy, found that clients experienced the therapist's guidance as helpful so long as it was in line with their hopes and expectations. Clients also experienced that they actively used the therapy sessions to work on themselves, but a lot of this reflective work was done covertly. Timulak (2007) conducted a qualitative meta-analysis of seven studies of client-identified impact of helpful events in a mixture of therapies. He found nine categories that replicated across studies. The most prevalent were awareness/insight/self-awareness and reassurance/support/safety, which occurred in all seven studies. Behavior change/problem solution, exploring feelings/emotional experiencing and feeling understood occurred in more than half of the studies.

In short, research on helpful factors has repeatedly found that the aspects and factors clients usually find helpful in therapy largely correspond to the concept of common factors, i.e. curative factors that are present in all or most psychotherapeutic methods, regardless of theoretical orientation. Common relational factors are the factors most often identified as helpful. However, there are also factors identified as helpful (or hindering) that would fall into the category of specific factors, i.e. curative factors identified as specific for a particular type of psychotherapy. For example Gershefski, Arnkoff, Glass, and Elkin (1996) and Levy, Glass, Arnkoff, Gershevski, and Elkin (1996) found that although common aspects of treatment (e.g. the therapist's helpfulness) were most frequently reported in a group of clients treated for depression, some aspects that were considered treatment specific were also reported (e.g. focus on interpersonal problems in IPT, focus on negative cognitions in CBT) and these aspects were experienced as helpful by some clients and hindering by other clients.

\section{Helpful factors in different types of therapy}

Although some of the reviews described above focus on helpful factors in one specific type of psychotherapy, others included therapies of different theoretical orientations, e.g. cognitive-behavioral, cognitive, eclectic/mixed, 
emotion-focused, experiential, humanistic, person centered and psychodynamic therapies. A very limited number of studies have specifically compared clients' experiences in different types of therapy. Results indicate that clients in different types of therapy may, to some extent, report different types of helpful factors, in some cases with the events matching the theory underlying the therapeutic approach. However, results differ somewhat between studies. For example, Elliott, James, Reimschuessel, Cislo, and Sack (1985) found that personal insight and reassurance were the most common impacts in a case of cognitive therapy whereas personal insight, awareness and client involvement were the most common impacts in a case of dynamicexperiential therapy. On the other hand, Llewellyn, Elliott, Shapiro, Hardy, and Fitz-Cozens (1988) reported that awareness was a typical impact reported in exploratory (psychodynamic therapy) whereas in prescriptive therapy (cognitive-behavioral therapy) a typical impact was problem solution. In a more recent study, Nilsson, Svensson, Sandell, and Clinton (2007) compared clients' experiences of change in cognitive-behavioral therapy (CBT) and psychodynamic therapy (PDT) and whether the clients were satisfied or not. They found that there were roughly equal numbers of satisfied and unsatisfied clients in both types of therapy, and that there were both similarities and differences in the experiences reported by the clients in each type of therapy. Satisfied clients in both forms of therapy reported that they had found new coping tools that helped them cope better with anxiety and that they had become better at coping with and understanding feelings. Satisfied CBT-clients experienced that they had regained a sense of being a normal person again and were better able to cope with their difficulties. Helpful factors were the therapists' expert knowledge of how to achieve the therapeutic goals, the clients' willingness to expose themselves to frightening things, exercises and exposure. Satisfied PDT-clients experienced a better self-understanding and had been able to put together a more coherent life story. Helpful factors were that the clients had been able to talk about and reflect on themselves as well as various aspects of the relationship with the therapist, for example that the therapist was emotionally supportive, nonjudgmental, accepting and professional.

\section{Hindering factors}

Comparatively few studies examine clients' experiences of hindering factors in therapy and those who do often discuss the difficulties associated with getting clients to disclose potentially negative or hindering experiences. 
Hindering factors are generally considered to be both under-reported and under-researched. Previous studies have found that clients are generally reluctant to talk about hindering experiences to their therapists (Farber, 2003; Levitt, 2002; Regan \& Hill, 1992; Rhodes, Hill, Thompson, \& Elliott, 1994). Even though clients are aware of the finer aspects of the relationship with the therapist there are things concerning their experiences in therapy that they do not tell even if invited by the therapist to share experiences of dissatisfaction. Instead they may use silence in response to difficult aspects of the therapy experience (Levitt, 2002), and they sometimes adapt to the therapist to keep the relationship intact (Lietaer, 1992; Rennie, 2002). In research interviews and questionnaires, clients seem slightly more willing to express hindering or unhelpful experiences (Dale, Allen, \& Measor, 1998; McKenna \& Todd, 1997) but they generally report fewer hindering than helpful factors (e.g. Levy et al., 1996), tend to give fewer comments to questions about unhelpful events and seem often to attribute the experienced difficulties to themselves (Lietaer, 1992).

In a study of helpful and non-helpful events in brief counseling interviews, Elliott (1985) developed a taxonomy of non-helpful therapist responses. He found six types of events that clients experienced as nonhelpful. Misperception events (where the clients felt misunderstood or inaccurately perceived) was the most common, followed by negative counselor reactions (e.g. experiencing the counselor as uninvolved or critical), unwanted responsibility (e.g. the counselor failing to provide a desired response or pressuring the client to talk in session or take action outside therapy). Other non-helpful events were experiences of counselor repetition (e.g. dwelling on the obvious, going over old ground), misdirection events (e.g. counselor interrupting or interfering with the client's disclosure and exploration, and the client experiencing unwanted thoughts initiated by the counselor. Lietaer (1992) reported similar results in an investigation of helpful and non-helpful processes in client-centered/experiential therapy. $\mathrm{He}$ found that the unhelpful experiences could be divided in two broad categories: The first category contained experiences related to the attitudes and interventions of the therapist, e.g. the therapist lacking warmth, involvement, or understanding, the therapist being not enough or overly passive/active, or the therapist giving inadequate interpretations. The second category contained experiences related to the client's process, e.g. the client hindering the conversation, preventing the conversation from deepening, or avoiding to talk about certain issues. Lietaer (1992) also noted that, in the first category, it was difficult to separate aspects of the relational climate from the specific therapist interventions, which was not the case with helping processes. The non-helpful processes were mostly described as events in 
which relational attitudes and interventions were intertwined, so that e.g. badly timed or misdirected interventions may have caused the client to experience the therapist as lacking warmth and understanding. Similar findings were reported in a recent study of seven dissatisfied patients' views of the therapeutic process and outcome (von Below \& Werbart, 2012). Patients did not describe one single factor or incident as a starting point for their dissatisfaction and they did not distinguish between the therapist's intervention and what was perceived as flews in the therapist's personality. Instead, experiences of the therapeutic relationship, suppositions of the therapist as a person, and an unproductive therapy were linked together in the patients' experience of dissatisfaction.

The finding that it can be difficult to separate relational aspects from technique aspects in some types of hindering factors links to other research findings highlighting the clients' preferences and expectations as important mediators of what is experienced as helpful or hindering. Gershefski el al. (1996) and Levy el al. (1996) found that in a group of clients treated for depression, although common aspects of treatment (e.g. the therapist's helpfulness) were most frequently reported as helpful, some aspects that were considered treatment specific were also reported (e.g. focus on interpersonal problems in IPT, focus on negative cognitions in CBT) and these aspects were experienced as helpful by some clients and hindering by other clients. Nilsson et al. (2007), in their comparison between CBT- and PDT-clients, found that dissatisfied clients in both CBT and PDT expressed a need for more therapy and believed that another form of therapy might be more beneficial to them. They did not share the therapists' ideas on how to work with their problems. Dissatisfied CBT-clients expressed thoughts and expectations that were more in line with PDT and vice versa.

\section{Helpful and hindering factors in different therapy modalities and in therapy with children and adolescents}

Although some of the first studies on helpful factors were studies on clients' experiences of group therapy there are considerably fewer studies on helpful factors in other therapy modalities than individual therapy. Concerning group therapy, Berzon et al. (1963), Bloch and Reibstein (1980), Bloch et al. (1979) and Moreno, Fuhriman, and Hileman (1995) all report helpful factors similar to the ones found in individual therapy (e.g. insight and emotional awareness) but also found that clients experienced as helpful factors which are specific for the group format and has to do with the social aspects of group therapy 
(e.g. vicarious learning, learning from interpersonal actions within the group, and being able to identify with other group members). In a comparison of helpful impacts in individual therapy and group therapy, Holmes and Kivlighan (2000) found that impacts concerning emotional awareness/insight and problem definition-change were less prevalent in the group setting than in the individual treatment whereas impacts concerning relationship climate and other versus self-focus were more common in group treatment than in individual treatment. Studies on hindering factors in group therapy are very scarce, but a study on interpersonal relations groups for counselor trainees (Doxsee \& Kivlighan, 1994) found that participants experienced hindering factors similar to the ones in individual therapy but also hindering factors specific for the group format, e.g. absence of a group member, experience of being discounted by a member or of the group leader, other member disconnection from the group, and member attack.

In couples and family therapy studies on clients' experiences of treatment are even scarcer (see e.g. Heatherington, Friedlander, \& Greenberg, 2005 for an overview). Only a handful of studies focus on the clients' subjective experiences: Greenberg, James, and Conry (1988) asked couples in emotionally focused couples' therapy (EFT) to identify helpful and hindering incidents and to describe how change occurred. Sells, Smith, and Moon (1996) interviewed clients about their perceptions of therapy effectiveness. Christensen, Russel, Miller, and Peterson (1998) asked clients in marital therapy to describe therapist facilitating behaviors and turning points in therapy and Helmeke and Sprenkle (2000) asked clients in couples' therapy to describe pivotal moments. Bowman and Fine (2000) asked couples who were in, or had newly completed, couples' therapy what they perceived as helpful and unhelpful about their therapy experiences and regarding the therapist's activities. The findings in all studies are similar and point to three types of processes and impacts that clients found helpful and important for a successful treatment: First, clients found emotional experiencing, hope, and a sense of safety helpful. This also includes feeling validated by one's partner or other family members, which is a factor specific for couples and family therapy. Second, clients experienced cognitive change, insight and awareness as helpful and, third, they experienced a strong connection with a caring, competent therapist who was well attuned to their presenting problems as helpful.

Similar aspects have been found in research on children's and adolescents' experiences of family therapy: A study on preadolescent children's experiences of family therapy (Stith, Rosen, McCollum, Coleman, $\&$ Herman, 1996) found that the children wanted to be involved in the therapy and come to the sessions even when they were not the focus, and that 
they found that talking about the problem helped both the them and their families. Thompson, Bender, Lantry, and Flynn (2007) interviewed 19 families with adolescents who were all in home-based treatment and found that participants preferred a collaborative therapy relationship with a calm, casual, authentic, caring and impartial therapist. Other helpful aspects that the participants expressed were gaining insights and developing new skills related to communication and family relationships. An interview study with previously suicidal adolescents found that enhanced self-understanding, communication, creative expression, the therapeutic relationship, and therapeutic strategies were five aspects of therapy that clients experienced as helpful (Paulson \& Everall, 2003). Binder, Moltu, Hummelslund, Henden Sagen, and Holgersen (2011) found that adolescents in ongoing therapies felt vulnerable and ambivalent in relation to the therapist at the beginning of therapy but found it helpful when the therapist demonstrated that (s)he was comfortable with being a therapist, helped managing dependency needs by establishing boundaries within the therapy relationship, recognized the client's individuality by respecting their personal boundaries, helped making experiences understandable and meaningful, and allowed mutuality and emotional closeness.

To summarize, research on helping and hindering factors in other therapy modalities and with children and adolescents seem to identify many of the same helping and hindering factors as in individual therapy with adults but also some helping and hindering factors that are specific for the therapy format. As in individual therapy findings from research on group, couples and family therapy also suggest that what clients find helpful or hindering depends to some extent on the client's individual expectations, preferences and interpersonal style. Helmeke and Sprengle (2000) found that clients within the couple may have different views on what they experienced as helpful in couples therapy, and Shaughnessy and Kivlighan (1995) found that members of the same therapy group differed in what they perceived as helpful and that the prevalence of reported events correlated to participants' interpersonal style.

\section{What do we know and where do we go from here?}

As described above, most qualitative research on clients' experiences of therapy has focused on describing and differentiating aspects of the therapy or the therapy process perceived as important by the clients. This makes good 
sense considering both that clients have "privileged access" to certain areas of the therapy process and their experience of it (Elliott \& James, 1989), and that substantial evidence indicates that clients' perspectives of therapy and the therapy process not only differ from therapists' and researchers' perspectives but also seem to be better predictors of outcome (Horvath el al., 2011). In short, previous research on clients experiences of therapy has repeatedly identified two broad types of helping factors that seem to occur across types of therapy and across therapy modalities: Clients often seem to find common relational factors helpful, for example the opportunity to talk freely to a competent, supportive, accepting, genuine, empathic and attuned therapist. Clients also seem to find factors related to problem-solving and the tasks/techniques of therapy helpful, for example gaining insight/awareness, and finding new tools to cope with or solve their problems. However, this second type of experiences is not as unanimously described as helpful as the first. Aspects that some clients experience as helpful may be experienced as hindering by others. Findings concerning hindering factors are fewer and even less clear cut but indicate that the clients' individual expectations, preferences and interpersonal style, and the therapists' relational attitude, therapeutic skill and timing may interact and influence which events, processes, interactions and interventions clients experience as hindering.

Although the research outlined above has broadened our understanding of what clients find important, helpful and hindering in therapy in important ways, there are still areas that need to be further explored. Like most of the studies described above, research within this area is usually based either on clients' choices of pre-set ranges of answers to researcher-constructed questionnaires and inventories about their experiences, or on clients' written or spoken retrospective accounts. The qualitative methods employed in data analysis are mostly based on a realist epistemology. They are primarily concerned with content and meaning and usually treat data as more or less accurate reflections of the clients' actual experiences. The same assumptions also underpin various efforts to create taxonomies of helpful and hindering factors in therapy. However, the strivings to classify clients' experiences of helpful and hindering factors, processes and events based on comparisons of similarities and differences entail the risk of overlooking or obscuring other important aspects of therapy and the therapy process: First, although interpersonal and relational aspects seem to play a role in clients' experiences of therapy, we know little about what actually goes on between clients and therapists during the moments in therapy which clients find important. In other words, there is a lack of qualitative studies focusing on detailed examination of the micro-processes of interaction within important events. Second, although most of us are well aware that what we say and how we say 
it is always, at least to some extent, shaped and limited by the context at hand, few studies examine or discuss how this affects clients' accounts of their experiences in therapy. In other words, there is a lack of studies examining how clients' accounts of their experiences in therapy are shaped and limited by the context in which they are produced, and the consequences of this.

The qualitative methods usually employed in this area of research are not suited to answer the kind of research questions that would fill in the gaps in our knowledge outlined above, but there are other qualitative methods that are. An alternative way to approach the study of important events would be to move from a realist epistemological standpoint to a social-constructionist perspective, which would allow a focus on the constitutive element in ways of talking about therapy as well as the micro-processes of therapeutic interaction.

\section{Social constructionist perspectives in psychotherapy research}

Psychotherapy research based on social constructionist perspectives has grown in the last decades and covers a range of issues in psychotherapy, approached from different research interests. Conversation analysis (CA) and discourse analysis (DA) are qualitative methods grounded in the basic assumptions of social constructionism. Both methods examine language in use rather that the psychological phenomena which are normally assumed to underlie talk and to be revealed by it. They share an emphasis on the importance of contextuality and a focus on language and interaction but there are also considerable differences in terms of underlying theory, analytic focus and methodology. Although both methods are highly suitable to address the kind of questions still waiting to be answered about clients' experiences of important aspects of therapy, there are relatively few studies employing these methods in psychotherapy research in general and in research on helpful factors or significant events in particular.

\section{Conversation analysis}

CA has its roots in the sociological tradition ethnomethodology (Garfinkel, 1967) and was developed to study the structure and process of naturally occurring talk in interaction (cf. Heritage, 1984; Peräkylä, 2003). CA seeks to 
"discover the things that persons in particular situations $d o$, the methods they use, to create the patterned orderliness of social life" (Garfinkel, 2002, p.6). Related approaches such as Membership Categorization Analysis (MCA), and recent developments such as discursive psychology (Edwards, 1995; Edwards \& Potter, 1992) share CA's origins in Sack's (1992) elaboration of Garfinkel's work in ethnomethodology but have slightly different analytical emphases.

CA makes some important theoretical assumptions about talk and interaction: First, talk is action and all actions, whether trivial everyday actions like greeting a friend or complex institutional actions like making a psychoanalytic interpretation, are accomplished through conversational interaction. Second, all talk is structurally organized and based on orderly procedures. This is not to say that all forms of conversations do, or must, occur in a standardized form according to a preexisting script, but rather that it is typical of human interaction that it routinely happens in an orderly and ordered way that can be observed and systematically analyzed through the study of turn-by-turn interaction in naturally occurring talk. Third, interaction is context shaped and context renewing. This is to say that what a specific action accomplishes, or what a given utterance is to be understood as, are never fixed but always co-constructed by the speakers in and for the moment of use. Meaning and intersubjective understanding is created in how the speakers demonstrate their understanding of a previous turn through the production of relevant next turns in the conversation. The speaker's next turn will then set a context that will shape the next speaker's turn, and so on.

CA seeks to explicate in great detail both how everyday conversations are organized and performed and how participants in more specific kinds of "institutional interaction" (e.g. doctors and patients, teachers and students) go about accomplishing their specific, institutionally ascribed, tasks. It has been used to study the structure and process of interaction between many different types of professionals and clients where spoken language is the means for the professional practice (Drew \& Heritage, 1992) and its potential value as a tool in psychotherapy process research has been pointed out repeatedly (see e.g. Gale, 1991; Madill, Widdicombe \& Barkham, 2001; Forrester \& Reason, 2006). Although the pacing has been slow there is a steadily growing number of CA or CA-inspired studies on psychotherapy, counseling and related areas. Issues that have been studied are for example problem formulations, (Davis, 1986; Buttny, 1990,1996; Madill et al., 2001), humor (Buttny, 2001), empathy (Wynn \& Wynn, 2006), psychoanalytic interpretations (Vehviläinen, 2003; Peräkylä, 2004), diagnostic formulations (Antaki, Barnes, \& Leudar, 2005b), cohesion in group therapy (Lepper \& Mergenthaler, 2005), self-disclosure (Antaki, Barnes, \& Leudar, 2005a; 
Leudar, Antaki, \& Barnes, 2006), therapeutic collaboration (Lepper \& Mergenthaler, 2007); resistance in psychoanalytic interaction (Vehviläinen, 2008), therapeutic change (Voutilainen, Peräkylä, \& Ruusuvuori, (2011), and present moment work (Kondratyuk \& Peräkylä, 2011). Some of these studies (e.g. Buttny, 2001; Antaki, Barnes, \& Leudar, 2005a, 2005b) take their point of departure more in language and interaction and their focus is consequently more on describing conversational practices in psychotherapy as institutional talk, and less on exploring research questions more typical of mainstream psychotherapy research. Others take their point of departure in specific psychotherapeutic theories and methods (e.g. Peräkylä, 2004; Vehviläinen, 2008; Kondratyuk \& Peräkylä, 2011), or in psychotherapy process research (Lepper \& Mergenthaler, 2005, 2007) and investigate central aspects of the therapy process and the therapeutic relationship. Regardless of their point of origin and their research interests, these studies have all added to our knowledge about conversational structures and practices in psychotherapy in important ways. However, CA has not been used to specifically investigate important events.

\section{Discourse analysis}

Discourse analysis (DA) refers to a broad and diverse range of methods that all developed out of the "turn to language" in social psychology in the 1970s and 1980s and the emergence of social constructionism (see e.g. van Dijk, 1997; Wetherell, Taylor, \& Yates, 2001 for introductions). The various approaches to DA have developed from different disciplines and utilize different analytical practices but all share a general focus on "the study of language in use" (Wetherell, Taylor, \& Yates, 2001, p.3). In line with the basic assumptions of social constructionism there is a general criticism of the cognitive psychological view of language as a direct representation of underlying psychological phenomena. A speaker's verbal claims are not automatically seen as a reflection of his or her opinion, attitude or experience, as is usually the case in much of traditional, mainstream psychology. Instead, language is seen as context-bound, functional and constitutive, and close attention is paid to how speakers use language in interaction. The overall focus of analysis is basically on how talk is organized in a specific context, and on the consequences of organizing it that way rather than any other way.

DA has been used to study a range of clinically related issues in psychology, health psychology and medicine, for example the underlying assumptions or historical trajectories behind diagnoses and clinical categories (e.g. Georgaca, 2000; Gillett, 1997), how mental health professionals 
construct their professional identity, justify their practices, and construct clinical categories and cases (e.g. Griffiths, 2001; Larsson, Loewenthal, \& Brooks, 2012; Moore \& Rae, 2009; Stevens \& Harper, 2007), and how discourses shape the experiences and views of clients and patients (e.g. Burns \& Gavey, 2004; Kelly, Holttum, Evans, \& Shepherd, 2012; Swann \& Ussher, 1995).

When employed in psychotherapy research, DA has primarily been used to examine psychotherapy process. The number of studies is moderate but increasing. Although there are some studies of individual therapy, family and couples therapy have been more frequently studied, which may be due to the fact that many therapies within these formats build on the same post-modern and social constructionist notions that DA. As pointed out by Avdi and Georgaca (2007) in a review on DA and psychotherapy, DA studies examining psychotherapy process span over a wide range of positions concerning their stance towards therapy: from critical positions aiming at macro-level examinations of the links between psychotherapy as a linguistic practice and broader, socially and culturally available systems of meaning and power relations, to positions aiming at uncovering and demonstrating the micro-level discursive and linguistic phenomena underlying psychotherapy processes. The degree of relevance and applicability of DA findings to clinical work varies (the same applies to CA findings), as do the researchers' intentions to provide such findings.

One aspect of the therapy process that has been examined in several DA studies on psychotherapy is the power relations between client and therapist, e.g. how therapists use their position as experts to further change in the client (e.g. Avdi, 2005; Nye, 1994), or how client and therapist both draw on broader, culturally available discourses related to power when negotiating the omnipresent and constantly changing power relations in therapy (e.g. Burman, 1992, 1995). Other DA studies have focused on the type of discursive resources clients draw on in therapy and how these shift over time (e.g. Avdi, 2005; Burck, Frosh, Strickland-Clark, \& Morgan, 1998; Guilfoyle, 2002), some researchers arguing that flexibility of discourse and range of subject positions are signs of improvement and positive outcome (e.g. Frosh, Burck, Strickland-Clark, \& Morgan, 1996; Madill \& Barkham, 1997; Madill \& Doherty, 1994). Another theme that has been examined in several studies is rhetorical and interactional features of talk in the situated context of the psychotherapy session, e.g. how displays of not remembering can be used as an interactional feature in couples therapy (Muntigl \& Choi, 2010), or how blame is managed in a family therapy (Stancombe \& White, 1997). Most studies focus on the interaction between client and therapist, but there are also studies focusing specifically on the therapist (e.g. Kurri \& 
Wahlström, 2007; Stancombe \& White, 2005). Although DA studies on psychotherapy processes have added in important ways to our understanding of the interactional and rhetorical nature of therapy and the complexity of the therapeutic relationship, there are also many aspects of psychotherapy and the therapy process that remain to been explored. There are no DA studies on clients' accounts of their experiences in therapy in general, or of important events in particular.

\section{Aim}

The overall aim of the present licentiate thesis is to explore client-identified important events in psychotherapy with a focus on studying therapy talk and talk about therapy from a social constructionist point of view. The central questions to be answered are:

1. What takes place between client and therapist in these events and how do the participants make sense of it while it is happening?

2. What types of events do clients describe as important?

3. How is clients' talk about these events shaped and organized by the use of specific discursive constructions and practices and what are the consequences of organizing it this way?

\section{Methodological approach}

\section{Participants}

Data were collected as part of a larger research project focusing on how therapists and clients identify, experience and handle important events in the therapeutic relationship. Eight pairs of clients and therapists participated. All clients, one man and seven women aged 20 to 57 years, were self-referred and presented with a wide range of problems suitable for out-patient treatment, e.g. anxiety, depression and various interpersonal difficulties. Clients' mean Global Assessment of Functioning Score (GAF) at the beginning of therapy was 58 (range 53-72), which indicate mild to moderate symptoms. The therapists, two men and six women aged 37 to 57 years, were 
all in a three year advanced training program to become chartered psychotherapists, licensed to practice by the Swedish National Board of Health and Welfare. They all had several years work experience in various health professions (e.g. psychologist, social worker) and a minimum of two years' experience doing psychotherapy under supervision. The therapies were short-term psychodynamic therapies with a relational-affect focus, consisting of 15-20 one-hour weekly sessions. All therapists received individual supervision once a week by trained and experienced supervisors throughout the therapies.

\section{Data collection}

All participating therapist-client pairs were asked to videotape three sessions: one at the beginning, one in the middle and one at the end of therapy. The video-recordings from the beginning of therapy were all made after the third session, the recordings from the middle of therapy were made at about the 10 th session and the recordings from the end at about the $15^{\text {th }}$ session. Semistructured interviews were conducted with both clients and therapists as soon as possible after each recorded session, usually immediately after the session but on some occasions up to 24 hours later. The length of the interviews was between 45 and 90 minutes and all interviews were audiotaped. In the interviews, the videotaped session was used as an aid to recall the session. The clients were always interviewed before their therapists. In the interviews, the clients were asked to "tell [me] about an occasion in this session when something happened in the contact between you and your therapist that you found important". The client was asked to locate each such occasion on the videotape and to indicate where it started and ended. The selected episodes were then timed and given verbal cues to enable later identification. When the client and the interviewer had watched the part of the tape containing the important event, the videotape was paused. The client was then asked to describe the event and his/her thoughts and feelings during it, including covert or withheld reactions. Further, the client was asked about his/her conceptions of the therapist's thoughts and feelings and (when applicable) whether s/he or the therapist had done anything to handle the situation, including the results of these attempts. An interview guide listing the general areas described above was used to ensure that all areas were covered for each important event the clients identified. 


\section{Ethical considerations}

This research project follows the ethical guidelines for social sciences developed by the Swedish Research Council (Vetenskapsrådet, 2002). Informed consent was obtained from all participants before the onset of data collection and individualized contracts were made with each participant specifying for what purposes, how, and for how long the data could be used.

To assure the anonymity of all concerned, names and other identifying contextual information have been omitted or altered in the data extracts discussed in Paper I and II.

An overall ethical reflection is that video recording therapy sessions that would not otherwise have been recorded, and repeatedly interviewing the participants about their experiences of the therapy and the therapeutic relationship during the course of therapy are actions that potentially (or even probably) influence the therapy process and/or the participants' perceptions of it. However, the nature and extent of the impact is difficult to predict and the participants' experiences of it are most likely highly individual. Also, in most forms of psychotherapy the participants' experiences of the ongoing therapy are something that client and therapist could (and would) talk about during sessions (or, in the therapists' case, in supervision). That both client and therapist talk to a third person, who is neither co-therapist nor supervisor, about these experiences is rare. For these reasons some basic guidelines were adopted throughout the data collection process in order to protect the integrity of both the participants and the ongoing therapy processes. First, the interviewer, who is a trained and experienced psychologist and psychotherapist, strived to be mindful of any signs of discomfort in the participants during the interviews. All participants were instructed to only share information about themselves and their experiences that they felt comfortable sharing. Second, clients were informed that their therapists would be told which therapy sequences the client had identified as important, but would not be told why the client found the event important and would not have access to any other information that the client had given during the interviews. Third, the interviewer also strived to be mindful of the risk of responding to participants in ways that overstepped the boundaries of the research interview and that might be perceived by the participants as therapeutic or supervisory. Fourth, the participants were informed that, should they wish to, they were free to talk to the other person in the therapeutic dyad (or, in the therapists' case, in supervision) about anything that had come up in the interviews.

In order to understand more about the impacts of the data collection method on the participants and the therapy process a focus group interview was conducted with the therapists after the data collection procedure was 
finished. The results of the focus group interview indicated that although the therapists felt that video recording the sessions and taking part in the interviews had had an impact on them, the clients and the therapy, the impact was seen as mostly beneficial.

\section{Data}

The data analyzed in the present licentiate thesis consists of the important events identified by the clients from the videotapes of their third therapy session (Paper I), and the interviews conducted with the clients immediately after their third therapy session (Paper II). (Data from other parts of the project will be reported in forthcoming papers.) All eight therapist-client pairs videotaped their third session. One of the session recordings failed due to technical problems. In this case the interview was conducted without the aid of the videotaped session. Instead, the client was asked to describe the important event in as much detail as possible. In total, the clients identified 18 important events, two of which came from the session that had not been videotaped. Six clients identified two events each, and two clients identified three events each.

The audiotaped interviews and the 16 videotaped events identified by the clients were transcribed verbatim. The interviews were transcribed noting pauses, emphases and nonverbal expressions and the videotaped events were transcribed in detail according to a simplified version of Jefferson's system for conversation analysis (Drew \& Heritage, 1992; Jefferson, 1985). All the client-identified important events contained turns involving both client and therapist. The average length was $2 \mathrm{~min} 50 \mathrm{~s}$ (range: $1 \mathrm{~min} 10 \mathrm{~s}$ to $6 \mathrm{~min} 50$ s). In the analytic procedure transcripts and tapes were used simultaneously. The data analysis was conducted using the Swedish original and translations of the excerpts included in Paper I and II were made by the first author after the analysis was completed.

\section{Analytic procedure}

\section{Analysis of the videotaped events}

In the analysis of the videotaped events conversation analysis (CA) was used as a tool. In CA the research process normally begins with a careful exploration of the whole data set in order to identify characteristic recurring 
interactional structures and practices. Based on the findings from the exploration, a relevant focus for further analysis is then selected. All examples of the phenomenon to be studied are collected from the data set and a detailed case-by-case, turn-by-turn analysis is performed. The aim is to demonstrate the different paths the interaction can take and how the phenomenon is produced by the participants' actions. As pointed out by e.g. Lepper and Mergenthaler (2007), when CA is applied to psychotherapy process research, depending on the focus of the study it might make more sense to identify clinically relevant sequences of the data set for exploration rather than to explore the whole set. This has been done based on theoretical concepts, e.g. selecting all sequences in a session of psychoanalysis where interpretations are made (Peräkylä, 2004) and with the help of quantitative measures, e.g. of verbal in session-behavior (Lepper \& Mergenthaler 2005, 2007). In the case of the present study, the client-identified important events were seen as indicators of clinical relevance and these events were the only part of the data set explored for characteristic recurring conversational structures and practices. In line with CA research tradition the data exploration was done between the authors as well as in a larger team involving experienced CA-researchers. When a relevant focus of analysis had been collaboratively established, a detailed case-by-case, turn-by-turn analysis was performed by the first author. To ensure the quality of the analysis, conversation analysis has developed a number of proof procedures specific of the method: First, all analytic claims must be grounded in observable data. Second, in order to be valid, analytic claims must be relevant from the perspective of the participant in the next conversational turn. In other words, meaning and intersubjective understanding is created and maintained by participants producing relevant next turns in the conversation. Third, the results of the analysis must be compared and contrasted to the knowledgebase accumulated over time by previous CA research. The evolving analyses were constantly discussed with the other authors and preliminary versions were presented and discussed in the CAteam at data sessions and seminars and successively refined and organized into descriptions of the three different interactional trajectories described in the Results and Discussion section of Paper I.

\section{Analysis of the interview data}

The analysis of the audiotaped interviews was made in two separate ways, with different aims. In the first part of the analysis the aim was to identify what clients said about the important events, to analyse their content and 
impact. All segments in the interviews that contained clients' accounts of important events were identified. Each segment was coded according to its immediate impact as described by the client. Events describing similar impacts were grouped together into primary categories and these were then considered in terms of their meaning, which involved returning to the text segments and segments of the audiotapes containing the accounts relating to each category and examining them for similarities. Categories with similar meanings were grouped together and named according to their shared meaning. The analysis was made primarily by the first author but was subsequently discussed with the other authors and refined until consensus was reached. Two independent auditors (clinical psychologists with several years' experience of psychotherapy research) were asked to compare the analysis with the data segments. Their observations were discussed among the authors and incorporated into the final categories.

In the second part of the analysis, the aim was to explore how the clients talked about the important events in the research interview situation. For this purpose, discourse analysis was used as a tool.

Compared to the first part of the analysis, one could say that rather than categorizing data according to content, the second part of the analysis aimed at organizing data into discourses and discursive practices, and exploring the consequences of drawing on these. This part of the analysis basically followed the research tradition in discourse analysis developed by Potter \& Wetherell (1987). According to this, the first phase of the analysis is to recognize patterns from data, the second phase is to form hypotheses about the functions and effects of these patterns, and the third phase is to ground the hypotheses in linguistic evidence. The analysis also drew on the "synthetic" (or eclectic) approach suggested by Wetherell and Edley (1999) for discourse analysis in psychology. This approach combines the analysis of recurring, culturally available patterns and themes across a larger sample, reflecting cultural beliefs and social norms, with a much more detailed examination of the discursive practices and resources used by individual speakers in the particular conversational context at hand.

In line with DA research tradition, the whole corpus of data was analyzed before any analytic claims were articulated. The extracts presented in the Results section of Paper II are used to illustrate the main arguments. They do not in any way constitute the sole basis of the analysis and should not be seen as attempts to summarize or describe the whole set of data. The DA research tradition recognize that in every analysis, other aspects of the data could be the focus for a valid analysis and the same extracts could have been analyzed differently. This openness for alternative readings of the same data is typical of DA research and is seen as one of the strengths of the approach. The 
quality of the analysis is evaluated on the basis of the transparency of the research process, and of the grounding of the analysis in in extracts, which allows the reader to judge the credibility of the results based on both the methodological rigour and the credibility of the claims.

The analysis consisted of reading the transcripts and listening to the audiotapes, identifying recurring images and systems of terms, and coding each segment of data according to recurring themes. The first author identified the relevant foci of analysis and performed the preliminary analysis, which was then discussed between the authors and successively refined and organized into the descriptions of the rhetorical strategies and devices presented in the Results section of Paper II. In the analytical process, three key concepts central to discourse analysis have been relevant: interpretative repertoires refer to the culturally available global patterns of sense-making and understanding that can be discerned in how speakers organize their talk, subject position refers to the rights and obligations available to those who use a particular repertoire, and accountability refers to the notions of normative responsibility to which the speaker relates. The overall focus of this part of the analysis was basically on how the clients' talk about important events was organized within the interview situation, and on the consequences of organizing it that way rather than any other way.

\section{Summary of included studies}

\section{Paper I: Client-identified important events in psychotherapy: Interactional structures and practices.}

Although previous research has extended our knowledge of the kind of events and processes clients find important, helpful and hindering in therapy, there is still a need to understand more about what goes in these moments. Specifically, very few qualitative studies of important events in psychotherapy focus on analyzing the interactional micro-processes between therapist and client in these moments. The aim of article I was to describe interactional structures and practices in client-identified important events by exploring what takes place between client and therapist in these events and how they make sense of it while it is happening. 


\section{Method}

Eight clients who had recently started short-term psychodynamic therapy were interviewed immediately after their third session and were asked to identify occasions in the therapy session when something they found important had happened in the contact between them and the therapist. A videotape of the therapy session was used as an aid to recall the session and the clients were asked to locate each important occasion on the videotape and to indicate where it started and ended. One of the recordings failed because of technical problems, but in the remaining seven recordings the clients identified a total of 16 important events. These events were transcribed verbatim in detail and analyzed case-by-case, turn-by-turn following the steps and procedures typical of conversation analysis. In the first step of the analysis the recordings and transcripts of the 16 selected episodes were carefully examined for recurring interactional structures and practices. A recurrent theme that was identified and selected for further analysis consisted of sequences in which client and therapist disagreed, spanning from minor differences in understanding or experience to more obvious disagreements and impasses. All sequences containing clients' expressions of disagreement were collected from the transcripts of the events to allow a detailed microanalysis. Six of the seven client-therapist pairs had at least one sequence containing client disagreement. 12 such instances were found across the data corpus.

\section{Results}

The analysis identified three different ways that the therapists handled disagreement. The first way was to orient to the client's cues of disagreement by inviting the client to elaborate on his or her point of view and to establish a shared understanding that is acceptable to both participants. This was the most common way, present in half of the episodes. The second way was to orient to the client's disagreement cues but define the therapist's own point view as more relevant than the client's. The third way was a single case in which the therapist did not in any way orient to the client's disagreement cues.

\section{Discussion}

A central feature of the present study is its starting point in client-identified important events. This is a slight departure from the usual procedure in CA 
research where, usually, the whole data set is searched for the phenomenon selected for study. On one hand, the client driven data selection was well in line with previous research suggesting that clients' experiences of therapy are related to outcome and are valid indicators of events containing clinically relevant ingredients. This is important since CA as a research method has nothing to say on clinical relevance and when applied to psychotherapy process research it is necessary to find reliable methods to identify clinically relevant sequences for analysis rather than analyzing the whole data set. On the other hand, it is important to take into consideration that focusing the analysis only to the client-selected events may have increased the risk of missing additional trajectories of interaction and deviant cases that may be present in other parts of the data. The results suggest that disagreement patterns may be an interesting focus for further exploration of microprocesses in important events.

One of the study's main results was that a majority of the clientidentified important events contained disagreement between client and therapist. This differs from what has been described in previous research on important events, where a recurring finding is that clients frequently identify positive relational therapist behaviors as important and helpful. At the same time this result highlights the different focus of the present study compared to previous research. Where previous research on important events has mostly focused on describing and categorizing clients' experiences this study, with conversation analysis as a tool, focus on the structure and process of interaction in these rather than on the participants expressed experiences. Whether the participating clients experienced these interactions as disagreements, whether it was the disagreements that made the clients find these sequences important, and whether the clients found these sequences important in a helpful or hindering way was outside the scope of the present study but raise important questions for further research.

\section{Paper II: Two ways of analyzing clients' accounts of important events in therapy.}

Previous research on important events in psychotherapy has added to our knowledge about processes, aspects and impacts that clients find important, helpful and hindering. However, most studies within this body of research treat the clients' accounts of important events as if they directly and 
transparently correspond to the clients' actual subjective experiences and to the underlying psychological phenomenon. They do not focus on or discuss how the clients' accounts of their experiences are shaped and limited by the context at hand. The aim of article II was to analyze what types of events clients describe as important, but also how their talk about these events is shaped and organized by the use of specific discursive constructions and practices, and the consequences of organizing it this way.

\section{Method}

Eight clients who had recently started short-term psychodynamic therapy were interviewed immediately after their third session and were asked to identify occasions when something that they found important happened in the contact between them and the therapist. A videotape of the session was used as an aid to recall the session. The clients were asked to locate each important event on the videotape and to locate where it started and ended. In the subsequent interview interviewer and client watched each event on the videotape and the client was then asked to describe the event and his/her thoughts and feelings during it, including covert or withheld reactions. The client was also asked about his/her conceptions of the therapist's thoughts and feelings and whether s/he and/or the therapist had done anything to handle the situation, including the results of these attempts. The interview were transcribed verbatim and analyzed in two separate ways. The first part of the analysis consisted of a content analysis and aimed at describing and categorizing the important events according to content and impact. The second part of the analysis aimed at exploring how the clients talked about the events within the interview situation and basically followed the steps and procedures of discourse analysis developed by Potter \& Wetherell (1987).

\section{Results}

Eighteen accounts of important events were found, 17 of these were described as helpful and one as nonhelpful. The first part of the analysis yielded descriptions of five different types of events which were named according to the impact described by the clients as: feeling validated/understood, gaining insight/understanding/awareness, exploring feelings/experiencing emotions, therapist omission/therapeutic impasse, and advice/problem-solving. The second part of the analysis identified one dominating interpretative repertoire, which we chose to label Therapy as a special kind of talk. In the interviews the clients draw on this repertoire to 
construct therapy as a special kind of talk that is different from everyday talk and is done in a special way that has to be understood, learned and mastered. The clients were also found to account for their level of therapy experience and expertise and to reject invitations to speculate on their therapist's thoughts and feelings. The discourse analysis demonstrated that these were two strategies clients used to handle attempts to trouble their positions as clients, while at the same time maintaining the special-kind-of-talk repertoire and addressing their accountability as clients within this framework.

\section{Discussion}

Looking at the results of the content analysis through the lens of the findings from the discourse analysis highlights how clients' accounts of important events are shaped and limited, not only by the participants ability to remember and verbally report their experiences in an accurate and nuanced way, or by the researcher's ability to meticulously collect and accurately analyze the data, but also by what is actually sayable within the conversational context of the research interviews. The findings highlight the need for psychotherapy researchers to become more aware of how the data we collect is shaped by socially and culturally available discourses and by the conversational context within which they are produced. This, in turn, suggests that social constructionist research methods could be a valuable tool that should be more frequently used in qualitative research on psychotherapy processes, alone or in combination with the qualitative methods traditionally used to capture and study important therapy events.

\section{Conclusive discussion and implications for further research}

The aim of this licentiate thesis was to explore client-identified important events in psychotherapy with a focus on studying therapy talk and talk about therapy from a social constructionist point of view. The first included paper focused on the interaction between clients and therapists in client-identified important events. It identified disagreements between client and therapist as a recurring conversational phenomenon within the events and proceeded to explore the different trajectories disagreements took and how they were both 
produced and handled by the participants. The second included paper examined clients' accounts of important events in two different ways, first by describing and categorizing them according to content and impact, and then by exploring how the clients' talk about these events was organized. The first analysis discerned five different types of events which were similar to the ones found in previous research on important events. The second analysis demonstrated how the clients' accounts of these events were shaped by a dominating interpretative repertoire of therapy as a special kind of talk that the clients drew on, and by the rhetorical strategies employed by the clients to handle their subject positions as clients, maintain the special-kind-of-talk repertoire and address their accountability as clients within the conversational setting of the research interviews. Taken together the findings demonstrate how qualitative methods based on a social-constructionist perspective can contribute to our understanding of client-identified important events and to psychotherapy process research in general by highlighting and describing participants' use of language in interaction, and its forms and functions within therapy session and in research interviews.

\section{Shifting focus - from categorization to contextuality}

Most previous research on helping and hindering factors take the position that it is indeed possible, at least to some extent, to capture and study clients' experiences of therapy. Previous studies have mainly focused on capturing, describing and differentiating the clients' experiences by collecting verbal or written accounts, which are seen as reflecting the clients' underlying experiences. Although findings seem to differ somewhat across studies concerning what clients find helpful, similar elements can be recognized as emerging under different labels in different studies. As to what clients experience as hindering, the findings are less clear cut and both subjective and relational factors seem to influence the clients' experiences. When findings are discussed, the concerns raised usually focus on the clients' ability or willingness to accurately remember and report the experience, or on the researchers' ability to collect and describe the data in a manner that reflects commitment, rigor, and mastery of the procedures associated with the chosen research method. What is seldom discussed is the relationship between experiences and how people talk about experiences, or the contextual influence on how people talk. 
To explain the differing findings from previous research on important events one could argue that perhaps there are no (or only a few) clearly recognizable factors or processes that clients experience as helpful or hindering. Or one could suggest that maybe there are, but more research is needed in order to better and in more detail describe, differentiate and label the factors and aspects that clients find helpful and hindering. If, instead, one takes on a social-constructionist view of talk as constitutive and contextual rather than as reflective of underlying psychological phenomena, the whole project of capturing and studying clients' experiences is put in a very different light. By shifting the focus from categorization to contextuality and by trying to describe how language is used when talking about important events or in the interactions within the events, methods like CA and DA suggest that there are other options than trying harder to describe and categorize the content of what is said. The path suggested by DA as an alternative to categorization of described experiences in therapy would be instead to explore the variability as well as the functional and contextual aspects of how clients talk about their experiences, and to describe the consequences of different speakers drawing on different interpretative repertoires and employing different discursive devices. CA, in turn, would suggest the even more radical step to leave interviews and questionnaires entirely behind and focus instead on naturally occurring talk, i.e. on the interactions between therapist and client in therapy sessions or within the important events. These suggested paths present some obvious challenges to the views on the role and scope of qualitative research traditionally held by psychotherapy process researchers but also offer interesting possibilities to explore previously unexplored aspects of psychotherapy and the psychotherapy process.

\section{Qualitative methods in psychotherapy process research}

As previously discussed, qualitative research on psychotherapy processes are mostly based on a realist epistemology and rely heavily on traditional forms of data analysis, such as various forms of thematic or content analysis and the advantages offered by such approaches. As pointed out by e.g. Elliott (2010) and Avdi and Georgaca (2007), qualitative methods employed in this area of research are both underused and rather limited in variation. In clinical 
practice, psychotherapy methods that are based on social constructionist perspectives and emphasize the importance of contextuality, interaction and the role of language are well established and accepted within the psychotherapy community. In psychotherapy research though, qualitative research methods based on the same philosophical and epistemological stance have had a much harder time to establish themselves as valuable tools which could help further our understanding of therapy and therapy processes.

One way in which the findings presented in this licentiate thesis add to our understanding of clients' experiences of therapy and the therapy process is by pointing out how clients' accounts are always shaped and limited by the context at hand. However, it is equally important to realize that the participants in our studies are not the only ones drawing on culturally available discourses and using rhetorical strategies and devices, but so do we as researchers. Our conceptualizations of psychotherapy and research, the questions we ask in inventories and interviews, and the way we describe and categorize our data are shaped and limited by the same mechanisms. The results presented in Paper I and Paper II suggest that it might be useful for psychotherapy researchers to become more aware of the consequences this might have on our data. A better understanding and awareness of these mechanisms could help us design the procedures for data collection and our interactions with study participants in ways that make their influence on our data more transparent. It may also lead us to broaden the range of methods used in psychotherapy process research to more often include socialconstructionist methods like CA and DA.

Importantly though, these conclusions do not imply that qualitative research methods based on a realist epistemology should be discarded in favor of methods based on a social constructionist epistemology. Rather, as the findings in this thesis hopefully go some way to demonstrate, using a wider range of qualitative methods, on their own or in concert with other qualitative (or quantitative) methods, may broaden our understanding of aspects of clients' experiences of therapy and of therapy processes. In the end, all qualitative methods used in psychotherapy process research to study clients' experiences of therapy must be evaluated against the aim underlying this whole area of research, which is to contribute to our understanding of how psychotherapy works and to help clinicians do a better job with their clients. In this respect, it might be fair to say that previous research on clients' experiences have come a longer way in demonstrating the value of its methods whereas CA and DA (lending the vocabulary from the literature on evidence-based practices) could perhaps be described as "promising", but with "not sufficient research yet to judge". However, while clinical practice should ideally be based on the integration of best available evidence with the 
needs and expectations of the individual client, the choice of research methods in psychotherapy process research should perhaps be based less on the number of useful findings in previous studies produced by a specific method, and more on the method's ability to present and communicate significant new and relevant knowledge in relation to the research questions waiting to be answered.

\section{Limitations, generalizability, and the claims and ambitions of CA and DA}

One obvious limitation to the studies included in this thesis is the low number of participants, which is too small for any generalizations to be made. However, neither CA nor DA is primarily concerned with making such claims, and this is important to bear in mind. In the CA study presented in Paper I, a main finding was that a majority of the important events identified by the clients contained disagreement between client and therapist. This is an interesting finding, considering that all but one of these events were described as helpful by the clients, and that previous research on helping factors has mostly emphasized common relational aspects of the therapeutic relationship, like a supportive, empathic and attuned therapist. As described above though, CA focus on the structure and process of talk in interaction and does not claim to capture any experiences that the speakers might have in the moment of the interaction. According to CA, an interaction that is structurally organized as a disagreement is not necessarily experienced as a disagreement, but neither can we be sure that it is not. Moreover, the finding that a majority of the client-identified important events contained disagreement between client and therapist, and the identification of three different ways the therapist used to handle it does not mean that there are no other ways that therapists handle disagreement, neither does it mean that other clients and therapists than the ones participating in the study would necessarily have disagreements as a recurring interactional feature in important events or, if they did, that other therapists would necessarily handle it in the same ways. CA does not make claims of statistical probability or normativity but argues that the details of the observed phenomena are massively reproducible. Applied to the findings presented here, this would mean that not all client-identified important events do, or must, occur in a standardized way. However, it is a core feature of talk that it happens in an orderly, and ordered, fashion that can be systematically described. 
Consequently, the ambitions (and the strength) of CA lies not in the potential to produce generalizable findings but in the patient accumulation of knowledge over time by constantly comparing and contrasting new findings and adding them to the existing base of CA knowledge on different kinds of interactions.

In the same way, one of the main findings in the DA study presented in Paper II was the demonstration of how clients' accounts of important events were shaped and limited by what was actually sayable within the context of the research interview. It is important to realize that these findings do not imply that the experiences the clients were talking about are not in some way real, they are just not something that DA, find it possible or relevant to make any claims about. Moreover, the finding that the clients in this study draw on the special-kind-of-talk repertoire does not mean that they would necessarily draw on the same repertoire on any other occasions. Nor does it mean that other clients would necessarily draw on it in similar contexts or when producing accounts of similar types of events. In other words, DA does not claim to produce generalizable results. In accordance with the central theoretical assumption that faced with the ever-changing range of situations in life, people will always draw on the discourses, which are available in the situation at hand, and suit their needs at a particular instance of discursive practice, the ambition of DA is instead to capture the variability and the context-bound and functional aspects of people's talk, and to examine the consequences of different speakers drawing on certain repertoires at certain times. Seen from this perspective it is seems more relevant to evaluate the quality of CA or DA studies according to other criteria than sample size or generalizability of findings.

In many areas of research in psychology and related fields, there is already an ongoing dialogue concerning quality criteria in qualitative research and the need to adapt the criteria according to the epistemological standpoint and the aims and ambitions of the particular methods (see e.g. Madill, Jordan, \& Shirley, 2000; Spencer, Ritchie, Lewis, \& Dillon, 2003). Although it is possible to identify a number of principles that underpin concepts of quality shared by many but not all epistemological perspectives, it is also important to acknowledge that some criteria are more relevant in the evaluation of some methods than of others, and that different qualitative methods put more or less weight on some criteria than on others. For example, methods with a realist epistemological standpoint (e.g. Grounded Theory, Thematic Analysis, Content Analysis) tend to judge quality based on criteria such as objectivity and reliability whereas methods with a social constructionist epistemological standpoint (e.g. Discourse Analysis, Conversation Analysis) tend to judge quality based on the methodological 
rigor and the transparency and credibility of the analysis as previously described. In psychotherapy process research, this development is still in its budding (e.g. Elliott, Fisher, \& Rennie, 1999; Reicher, 2000), which may be one possible explanation to why social constructionist methods still have not been able to establish themselves as valuable research tools. Deepening this discussion and striving to include the larger community of psychotherapy researchers seem like an important step towards broadening the range of qualitative methods used in psychotherapy process research.

\section{Implications for future research}

The findings presented in this licentiate thesis point out the need to broaden the range of qualitative methods used in psychotherapy research in general and indicate the potential value of methods like CA and DA to psychotherapy process research in particular. Methods like CA and DA, which are based on social-constructionist perspectives and focus on examining talk and interaction in its own right rather than as a means of examining some underlying psychological phenomenon, are sparingly used within this area of research, which means that there are numerous research questions and research areas still waiting, and needing, to be explored. On a smaller scale, findings from the two studies included in this thesis suggest some interesting paths for future research: First, the findings from the CA study suggest that disagreement patterns in the interaction between client and therapist might be an interesting path for further exploration. One way would be to extend the analysis to include for example client selected important events from the middle and end of the therapies. Other ways might be to identify disagreement sequences in the data based on structural features, or to explore disagreement patterns in for example alliance ruptures, or in sequences which the clients identified as hindering or as containing experiences of disagreement. It would also be interesting to investigate if, and how, specific interactional patterns in expressing and handling disagreement are associated with specific types of events, with the quality of the therapeutic relationship, or with outcome. Second, the findings from the DA study suggest that a natural next step would be to examine clients' accounts of important events from the middle and end of therapy in order to examine shifts over time in the type of discursive resources the clients draw on. Another path would be to compare how clients and therapists talk about the same events. On a larger scale, our knowledge, both about the micro-processes of interaction in psychotherapy and about how the data we collect in research interviews and 
questionnaires is shaped by contextual and interactional factors, is still limited. There is, to put it simply, much, much more to be learned about the role of language and interaction in psychotherapy and in psychotherapy process research.

\section{References}

Antaki, C., Barnes, R., \& Leudar, I. (2005a). Self-disclosure as a situated interactional practice. British Journal of Social Psychology, 44, 1-20.

Antaki, C., Barnes, R., \& Leudar, I. (2005b). Diagnostic formulations in psychotherapy. Discourse Studies, 7(6), 627-647.

Avdi, E. (2005). Discursively negotiating a pathological identity in the clinical dialogue: Discourse analysis of family therapy. Psychology and Psychotherapy: Theory, Research and Practice, 78, 1-19.

Avdi, E., \& Georgaca, E. (2007). Discourse analysis and psychotherapy: A critical review. European Journal of Psychotherapy and Counselling, 9, 157-176.

Berzon, B., Pious, C., \& Farson, R. C. (1963). The therapeutic event in group psychotherapy: A study of subjective reports by group members. Journal of Individual Psychology, 19, 204-212.

Binder, P.-E., Moltu, C., Hummelsund, D., Henden Sagen, S., \& Holgersen, H. (2011). Meeting an adult ally on the way out in the world: Adolescent patients' experience of useful psychotherapeutic ways of working at an age when independence really matters. Psychotherapy Research, 21, 554566.

Bloch, S., \& Reibstein, J. (1980). Perception by patients and therapists of therapeutic factors in group psychotherapy. British Journal of Psychiatry, 137, 274-278.

Bloch, S., Reibstein, J., Crouch, E., Holroyd, P., \& Themen, J. (1979). A method for the study of therapeutic factors in group psychotherapy. British Journal of Psychiatry, 134, 257-263.

Bowman, L., \& Fine, M. (2000). Client perceptions of couples' therapy: Helpful and unhelpful aspects. The American Journal of Family Therapy, 28, 295-310.

Burck, C., Frosh, S., Strickland-Clark, L., \& Morgan, K. (1998). The process of enabling change: A study of therapist interventions in family therapy. Journal of Family Therapy, 20, 253-267. 
Burman, E. (1992). Identification and power in feminist therapy: A reflexive history of a discourse analysis. Women's Studies International Forum, 15, 487-498.

Burman, E. (1995). Identification, subjectivity and power in feminist therapy. In J. Siegfried (Ed.), Therapeutic and everyday discourse as behavior change: Towards a micro-analysis in psychotherapy process research (pp. 468-489). Norwood: Ablex.

Burns, M., \& Gavey, N. (2004). 'Healthy weight' at what cost? 'Bulimia' and a discourse of weight control. Journal of Health Psychology, 9(4), 549565.

Buttny, R. (1990). Blame-account sequences in therapy: The negotiation of relational meaning. Semiotica, 78(3-4), 219-247).

Buttny, R. (1996). Client's and therapist's joint construction of the client's problem. Research on Language and Social Interaction, 29(2), 125-153.

Buttny, R. (2001). Therapeutic humor in retelling the client's tellings. Text, 21(3), 303-326.

Christensen, L.L., Russel, C.S., Miller, R.B, \& Peterson, C.M. (1998). The process of change in couples' therapy: A qualitative investigation. Journal of Marital and Family Therapy, 24, 177-188.

Dale, P., Allen, J., \& Measor, L. (1998). Counselling adults who were abused as children: Clients' perceptions of efficacy, client-counsellor communication, and dissatisfaction. British Journal of Guidance and Counselling, 26, 141-157.

Davis, K. (1986). The process of problem (re)formulation in psychotherapy. Sociology of Health and Illness, 8, 44-77.

Doxsee, D.J., \& Kivlighan, D.M., Jr. (1994). Hindering events in interpersonal relations groups for counselor trainees. Journal of Counseling and Development, 72, 621-626.

Drew, P., \& Heritage, J. (1992). Analyzing talk at work: An introduction. In P. Drew \& J. Heritage (eds.), Talk at work (pp. 3-65). Cambridge, UK: Cambridge University Press.

Edwards, D. (1995). Sacks and psychology. Theory and Psychology, 5(3), 579-597.

Edwards, D., \& Potter, J. (1992). Discursive Psychology. London: Sage.

Elliott, R. (1985). Helpful and non-helpful events in brief counseling interviews: An empirical taxonomy. Journal of Counseling Psychology, 32, 307-322.

Elliott, R. (2010). Psychotherapy change process research: Realizing the promise. Psychotherapy Research, 20(2), 123-135. 
Elliott, R., Fischer, C.T., \& Rennie, D.L. (1999). Evolving guidelines for publication of qualitative research studies in psychology and related fields. British Journal of Clinical Psychology, 38, 215-229.

Elliot, R., \& James, E. (1989). Varieties of client experience in psychotherapy: A review of the literature. Clinical Psychology Review, 9 , 443-467.

Elliott, R., James, E., Reimschuessel, C., Cislo, D, \& Sack, N. (1985). Significant events and the analysis of immediate therapeutic impacts. Psychotherapy, 22, 620-630.

Elliott, R., Bohart, A.C., Watson, J.C., \& Greenberg, L.S. (2011). Empathy. In J.C. Norcross (Ed.) Psychotherapy relationships that work: Evidencebased responsiveness ( $2^{\text {nd }}$ ed., pp. 132-152).New York: Oxford University Press.

Farber, B.A. (2003). Patient self-disclosure: A review of the research. Journal of Clinical Psychology / In Session, 59,589-600.

Forrester, M., \& Reason, D. (2006). Conversation analysis and psychoanalytic psychotherapy research: Question, issues, problems and challenges. Psychoanalytic Psychotherapy, 20, 40-64.

Frosh, S., Burck, C., Strickland-Clark, L., \& Morgan, K. (1996). Engaging with change: A process study of family therapy. Journal of Family Therapy, 18, 141-161.

Gale, J.E. (1991). Conversation analysis of therapeutic discourse: The pursuit of a therapeutic agenda. Norwood, NJ: Ablex.

Garfinkel, H. (1967). Studies in ethnomethodology. Engelwood Cliffs, NJ: Prentice-Hall.

Garfinkel, H. (2002). Ethnomethodology's program: Working out Durkheim 's aphorism. Lanham, MD: Rowman \& Littlefield.

Georgaca, E. (2000). Reality and discourse: A critical analysis of the category of 'delusions'. British Journal of Medical Psychology, 73, 227242.

Gershefski, J.J., Arnkoff, D.B., Glass, C.R., \& Elkin, I. (1996). Clients' perceptions of treatment for depression: I. Helpful aspects. Psychotherapy Research, 6, 233-247.

Gillett, G. (1997). A discursive account of multiple personality disorder. Philosophy, Psychiatry and Psychology, 4, 213-222.

Greenberg, L.S. (2007). A guide to conducting a task analysis of psychotherapeutic change. Psychotherapy Research, 17, 15-30.

Greenberg, L.S., Elliott, R., \& Lietaer, G. (1994). Research on humanistic and experiential psychotherapies. In A.E. Bergin \& S.L. Garfield (Eds.), Handbook of psychotherapy and behavior change ( $4^{\text {th }}$ ed., pp. 509-539). New York: Wiley. 
Greenberg, L.S., James, P.S., \& Conry, R. (1988). Perceived change processes in emotionally focused therapy. Journal of Family Psychology, 2, 5-23.

Griffiths, L. (2001). Categorizing to exclude: The discursive construction of cases in community mental health teams. Sociology of Health and Illness, 23, 678-700.

Guilfoyle, M. (2002). Rhetorical processes in therapy: The bias of selfcontainment. Journal of Family Therapy, 24, 298-316.

Heatherington, L., Friedlander, M., \& Greenberg, L. (2005). Change process research in couple and family therapy: Methodological challenges and opportunities. Journal of Family Psychology, 19, 18-27.

Helmeke, K.B., \& Sprenkle, D.H. (2000). Clients' perceptions of pivotal moments in couples' therapy: A qualitative study of change in therapy. Journal of Marital and Family Therapy, 26, 469-483.

Heritage, J. (1984). Garfinkel and ethnomethodology. Cambridge, UK: Polity Press.

Holmes, S.E., \& Kivlighan, D.M., Jr. (2000). Comparison of therapeutic factors in group and individual treatment processes. Journal of Counseling Psychology, 47, 478-484.

Horvath, A.O., Del Re, A.C., Flückiger, C, \& Symonds, D. (2011). Alliance in individual psychotherapy. In J.C. Norcross (Ed.) Psychotherapy relationships that work: Evidence-based responsiveness $\left(2^{\text {nd }}\right.$ ed., pp. 2569).New York: Oxford University Press.

Howe, D. (1993). On being a client: Understanding the process of counseling and psychotherapy. London: Sage.

Jefferson, G. (1985). An exercise in the transcription and analysis of laughter. In T.A. van Dijk (Ed.), Handbook of discourse analysis: Vol.3, Discourse and dialogues (pp. 25-34), London: Academic press.

Kelly, V., Holttum, S., Evans, C., \& Shepherd, M. (2012). A discourse analysis of power in relation to PSYCLOPS (Psychological outcome profiles) in the context of CBT for psychosis. Counselling and Psychotherapy Research, 12, 247-256.

Kondratyuk, N., \& Peräkylä, A. (2011). Therapeutic work with the present moment: A comparative conversation analysis of existential and cognitive therapies. Psychotherapy Research, 21, 316-330.

Kurri, K., \& Wahlström, J. (2005). Placement of responsibility and moral reasoning in couple therapy. Journal of Family Therapy, 27, 352-369.

Larsson, P., Loewenthal, D., \& Brooks, O. (2012). Counselling psychology and schizophrenia: A critical discursive account. Counselling Psychology Quarterly, 25, 31-47. 
Lepper, G., \& Mergenthaler, E. (2005). Exploring group processes. Psychotherapy Research, 15, 433-444.

Lepper, G., \& Mergenthaler, E. (2007). Therapeutic collaboration: How does it work? Psychotherapy Research, 17, 576-587.

Leudar, I., Antaki, C., \& Barnes, R. (2006). When psychotherapists disclose personal information about themselves to clients. Communication \& Medicine, 3, 27-41.

Levitt, H.M. (2002). The unsaid in the psychotherapy narrative; Voicing the unvoiced. Counselling Psychology Quarterly, 15, 333-350.

Levy, J.A., Glass, C.R., Arnkoff, D.B., \& Gershefski, J.J., \& Elkin, I. (1996). Clients' perceptions of treatment for depression: II. Problematic or hindering aspects. Psychotherapy Research, 6, 249-262.

Lietaer, G. (1992). Helping and hindering processes in clientcentered/experiential psychotherapy. In S.G. Toukmanian \& D.L. Rennie (Eds.), Psychotherapy process research: Pragmatic and narrative approaches (pp. 134-162.). Newbury Park CA: Sage.

Lipkin, S. (1948). The client evaluates nondirective psychotherapy. Journal of Consulting Psychology, 12, 137-146.

Llewellyn, S.P., Elliott, R., Shapiro, D.A., Hardy, G., \& Firth-Cozens, J. (1988). Client perceptions of significant events in prescriptive and exploratory periods of individual therapy. British Journal of Clinical Psychology, 27, 105-114.

Madill, A., Barkham, M. (1997). Discourse analysis of a theme in one successful case of brief psychodynamic-interpersonal psychotherapy. Journal of Counseling Psychology, 44(2), 232-244.

Madill, A., \& Doherty, K. (1994). So you did what you wanted then: Discourse analysis, personal agency and psychotherapy. Journal of Community and Applied Social Psychology, 4, 261-273.

Madill, A., Jordan, A., \& Shirley, S. (2000). Objectivity and reliability in qualitative analysis: Realist, contextualist and radical constructionist perspectives. British Journal of Psychology, 91, 1-20.

Madill, A., Widdicombe, S., \& Barkham, M. (2001). The potential of conversation analysis for psychotherapy research. Counselling Psychologist, 29, 413-434.

Martin, D.J., Garske, J.P., \& Davis, K.M. (2000). Relation of the therapeutic alliance with outcome and other variables: A meta-analytic review. Journal of Consulting and Clinical Psychology, 68, 438-450.

McKenna, P.A., \& Todd, D.M. (1997). Longitudinal utilization of mental health services: A timeline method, nine retrospective accounts, and a preliminary conceptualization. Psychotherapy Research, 7, 383-395. 
McLeod, J. (1990). The client's experience of counselling and psychotherapy: A review of the literature. In D. Mearns \& W. Dryden (Eds.), Experiences of counseling in action (pp.1-19). London: Sage.

Moore, T., \& Rae, J, (2009). 'Outsiders': How some counseling psychologists construct themselves. Counselling Psychology Quarterly, 22, 381-392.

Moreno, J.K., Fuhriman, A., \& Hileman, E. (1995). Significant events in a psychodynamic psychotherapy group for eating disorders. Group, 19, 5662.

Muntigl, P., \& Choi, K.T. (2010). Not remembering as a practical epistemic resource in couples' therapy. Discourse Studies, 12(3), 331-356.

Nilsson, T., Svensson, M., Sandell, R., \& Clinton, D. (2007). Patients' experiences of change in cognitive-behavioral therapy and psychodynamic therapy: a qualitative comparative study. Psychotherapy Research, 17, 553-566.

Nye, C.H. (1994). Narrative interaction and the development of client autonomy in clinical practice. Clinical Social Work Journal, 22(1), 43-57.

Orlinsky, D. E., \& Howard, K. I. (1967). The good therapy hour: Experiential correlates of patients' and therapists' evaluations of therapy sessions. Archives of General Psychiatry, 16, 621-632.

Paulson, B.L., \& Everall, R.D. (2003). Suicidal adolescents: helpful aspects of psychotherapy. Archives of Suicide Research, 7, 309-321.

Peräkylä, A. (2003). Conversation analysis. In C. Seale, J. Gubrium, G. Gobo \& D. Silverman (Eds.), Qualitative research practice (pp. 153-166). London: Sage.

Peräkylä, A. (2004). Making links in psychoanalytic interpretations: A conversation analytical perspective. Psychotherapy Research. 14, 289307.

Potter, J., \& Wetherell, M. (1987). Discourse and social psychology. London: Sage.

Regan, A., \& Hill, C. (1992). Investigation of what clients and counselors do not say in brief psychotherapy. Journal of Counseling Psychology, 39, 168-174.

Reicher, S. (2000). Against metodolatry: Some comments on Elliott, Fisher, \& Rennie. British Journal of Clinical Psychology, 39, 1-6.

Rennie, D.L. (2002). Experiencing psychotherapy: Grounded theory studies. In R.C. Page, J.F. Weiss, Litaer, G. (Eds.), Humanistic psychotherapies: Handbook of research and practice (pp. 117-144). Washington, DC: American Psychological Association. 
Rhodes, R.H., Hill, C.E., Thompson, B.J., \& Elliott, R. (1994). Client retrospective recall of resolved and unresolved misunderstanding events. Journal of Counseling Psychology, 41, 473-483.

Rice, L., \& Greenberg, L. (Eds.) (1984). Patterns of change: An intensive analysis of psychotherapeutic process. New York: Guilford.

Sacks, H. (1992). Lectures on conversation (2 vols.). Edited by Gail Jefferson with introductions by E.A. Schegloff. Oxford: Basil Blackwell.

Safran, J., \& Muran, C. (2003). Negotiating the therapeutic alliance: A relational treatment guide. New York: Guilford Press.

Sells, S.P., Smith, T.E., \& Moon, S. (1996). An ethnographic study of client and therapist perceptions of therapy effectiveness in a university-based training clinic. Journal of Marital and Family Therapy, 22, 321-342.

Shaughnessy, P., \& Kivlighan, D.M. (1995). Using group participants' perceptions of therapeutic factors to form client typologies. Small Scale Research, 26, 250-268.

Snyder, W.U. (1961). The psychotherapy relationship. New York: Macmillan.

Spencer, L., Ritchie, J., Lewis, J., \& Dillon, L. (2003). Quality in qualitative evaluation: A framework for assessing research evidence. London: National Centre for Social Research.

Stancombe, J., \& White, S. (1997). Notes on the tenacity of the therapeutic presupposition in process research: Examining the artfulness of blamings in family therapy. Journal of Family Therapy, 19, 21-41.

Stancombe, J., \& White, S. (2005). Cause and responsibility: Towards an interactional understanding of blaming and 'neutrality' in family therapy. Journal of Family Therapy, 27, 330-351.

Stevens, P., \& Harper, D.J. (2007). Professional accounts of electroconvulsive therapy: A discourse analysis. Social Science and Medicine, 64, 1475-1486.

Stith, S.M., Rosen, K.H., McCollum, E.E., Coleman, J.U., \& Herman, S.A. (1996). The voices of children: Preadolescent children's experiences in family therapy. Journal of Marital and Family Therapy, 22, 69-86.

Strupp, H. H., Fox, R. E., \& Lessler, K. (1969). Patients view their psychotherapy. Baltimore: Johns Hopkins University press.

Swann, C.J., \& Ussher, J.M., (1995). A discourse analytic approach to women's experience of premenstrual syndrome. Journal of Mental Health, 4, 359-367.

Thompson, S.J., Bender, K., Lantry, J., \& Flynn, P.M. (2007). Treatment engagement: Building therapeutic alliance in home-based treatment with adolescents and their families. Contemporary Family Therapy, 29, 39-55. 
Timulak, L. (2007). Identifying core categories of client-identified impact of helpful events in psychotherapy: A qualitative meta-analysis. Psychotherapy Research, 17, 305-314.

Timulak, L. (2010). Significant events in psychotherapy: An update of research findings. Psychology and Psychotherapy: Theory, Research and Practice, 83, 421-477.

van Dijk, T.A. (1997). The study of discourse. In T.A. van Dijk (Ed.), Discourse studies: A multidisciplinary introduction (Vol. 1, pp. 1-34). London: Sage.

Vehviläinen, S. (2003). Preparing and delivering interpretations in psychoanalytic interaction. Text, 23(4), 573-606.

Vehviläinen, S. (2008). Identifying and managing resistance in psychoanalytic interaction. In A. Peräkylä, C. Antaki, S. Vehviläinen \& I. Leudar (Eds.), Conversation analysis and psychotherapy (pp. 120-138). Cambridge, UK: Cambridge University Press.

Vetenskapsrådet (2002). Forskningsetiska principer inom humanistisksamhällsvetenskaplig forskning. Stockholm: Vetenskapsrådet.

von Below, C., \& Werbart, A. (2012). Dissatisfied psychotherapy patients: A tentative conceptual model grounded in the participants' view. Psychoanalytic Psychotherapy, 26, 211-229.

Voutilainen, L., Peräkylä, A., \& Ruusuvuori, R. (2011). Therapeutic change in interaction: Conversation analysis of a transforming sequence. Psychotherapy Research, 21, 348-365.

Wetherell, M., \& Edley, N. (1999). Negotiating hegemonic masculinity; imaginary positions and psycho-discursive practices. Feminism \& Psychology, 9(3), 335-356.

Wetherell, M., Taylor, S., \& Yates, S.J. (Eds.) (2001). Discourse theory and practice: A reader. London: Sage.

Wynn, R., \& Wynn, M. (2006). Empathy as an interactionally achieved phenomenon in psychotherapy. Characteristics of some conversational resources. Journal of Pragmatics, 38, 1385-1397.

Yardley, L. (2000). Dilemmas in qualitative research. Psychology and Health, 15, 215-228. 


\section{Acknowledgements in Swedish}

Många människor har på alla möjliga och omöjliga sätt bidragit till att detta mycket långsamma projekt inte helt har havererat längs vägen. Några av er vill jag särskilt lyfta fram och till alla er andra vill jag säga att även om era namn inte finns med i tryck så skall ni veta att ni har gjort både avtryck och intryck. Mitt varmaste tack till er alla!

Först och främst vill jag tacka alla deltagare, ni generösa och modiga människor som gav mig tillträde till era terapisessioner, tålmodigt lät er intervjuas och oförskräckt hanterade både teknisk utrustning och långa frågeformulär. Ni har bidragit till att vi nu vet lite mer om viktiga händelser $\mathrm{i}$ psykoterapi, kunskap som förhoppningsvis kan bidra till ännu en pusselbit i vår förståelse av hur terapi fungerar.

Karin Zetterqvist Nelson. Min huvudhandledare, som under arbetets gång även har dubblerat i många andra roller: kollega, lärare, bollplank, boktipsare och vän, för att bara nämna några. Du har lärt mig det mesta jag kan om att forska, undervisa och överleva i universitetsmiljö, du lappade ihop både mig och det här projektet när vi låg i spillror, du är fantastisk på att läsa och ge konstruktiv återkoppling och jag vet ingen som ger så bra boktips som du. Ett tack rymmer bara en bråkdel av allt jag skulle vilja säga, men ändå: tack!

Rolf Holmqvist. Min biträdande handledare, som alltid generöst har delat med sig av sina enorma kunskaper och varit öppen för prat om väldigt mycket mer än "bara" terapi. Din nyfikenhet, generositet och prestigelöshet gör arbetet roligt även när det är jobbigt och jag har lärt mig massor av dig. Tack! Du är dessutom den enda jag vet som kan vara på flera ställen samtidigt och som inte har någon ställtid alls. Det hoppas jag du kan tänka dig att lära mig framöver!

Birgitta Elmquist och Leif Havnesköld. Dörröppnare och brobyggare. Tack för att ni hjälpte mig att få tillgång till en värld jag annars inte så lätt hade kunnat komma in $\mathrm{i}$.

Ann-Charlotte Hermansson. Vän, tidigare kollega, klippa i alla lägen och tillsammans med Karin den som lärt mig det mesta man behöver veta om livet som lärare och forskare på ett universitet. Utan ditt stöd hade jag förmodligen gett upp för länge sedan! Jag är hedrad över att du lämnade 
Vinjettpärmen i min vård och hoppas du vet att jag kommer och lyfter tunga saker närhelst det behövs.

Lars Back, Annika Ekeblad, Fredrik Falkenström, Mattias HolmqvistLarsson, Börje Lech, Clara Möller, Björn Philips och alla andra i och omkring forskargruppen, som med samma värme och goda humör har pärlat, rest, provat öl och låtit krusade ja:n och postmodern dataanalys få utrymme under våra möten.

Lise Bergman Nordgren, Maria Jannert och Hugo Hesser. Kollegor och vänner från andra sidan galaxen. Tack för att ni gör mina arbetsdagar mycket rikare och roligare. Same same, but different!

Katarina Byttner, Christina Carlsson och Lilli Ann Rabe-Lyttkens.

Långvariga vänner, som finns där för både terapiprat och prat om terapi men som framför allt envisas med att förmedla att det också finns annat här i livet och att ni gillar mig som jag är. Särskilt när jag behöver det som mest. Kroppskontakt!

Min familj, både min ursprungsfamilj och vi som hittat och valt varandra längs vägen. Tack för att ni finns! 


\section{Papers}

The articles associated with this thesis have been removed for copyright reasons. For more details about these see:

http://urn.kb.se/resolve?urn=urn:nbn:se:liu:diva-111919 